\title{
Preparation and Magnetic Properties of $\mathrm{BaFe}_{12-2 x} \mathrm{Co}_{x-y} \mathrm{Sn}_{x} \mathrm{Ni}_{y} \mathrm{O}_{19}$ Particles
}

\author{
C.H. Lin, P.C. Kuo and J.S. Shih \\ Department of Materials Science, Tsing Hua University Hsinchu, Taiwan, China \\ * Institute of Materials Science, Taiwan University Taipei, Taiwan, China
}

\begin{abstract}
BaFe12-2x $\mathrm{CO}_{2}-\mathrm{Sn}_{x} \mathrm{Ni}_{3} \mathrm{O}_{1}$, hexagonal-plated-shaped bariun ferrite powders were prepared by chemical pricipitation and subsequent heat treatment to investigate the effects of $\mathrm{Ni}$ ion on the magnetic properties of the barium ferrite powders. Experimental results indicates that if the $y$ value in the chemical formula is varied and the $x$ value is aintained constant, i.e. the partial replacement of Co ion by Ni ion, the particle size and $a_{s}$ of the powders were reduced; furthermore, the $H_{c}$ value of the powders would be waximized at a certain $y$ value. If the $x$ value is varied and maintained $y=0.5 x$, the large the addition of $\left(\mathrm{Co}_{x} / 2 \mathrm{Ni}_{x} / 2 \mathrm{Sn}_{x}\right)$ ions causes the wore of a decrease in the $\sigma$ value, $H_{c}$ value, and curie temperature.
\end{abstract}

\section{INTRODUCTION}

Hexagonal-plated-shaped barium ferrites are a highly promising material for perpendicular recording media, if $i$ ts $H_{c}$ can be reduced for easier writing by the magnetic head. The $H_{c}$ of barium ferrites can be reduced by simultaneously adding $\mathrm{Co}$ and $\mathrm{Sn}$ ions [1] to replace some $\mathrm{Fe}_{2} \mathrm{O}_{3}$. Since $\mathrm{Ni}$ ion is a component of $\mathrm{Ni}-\mathrm{Zn}$

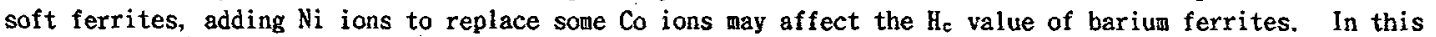
report, the effects of magnetic properties of barium ferrites are examined by (1) partially replacing $\mathrm{Ni}$ ion for $\mathrm{Co}_{\mathrm{i}}$ at a fixed $\mathrm{Sn}$ ion, i.e. changing $\mathrm{y}$ value and maintaining the $\mathrm{x}$ value constant in $\mathrm{BaFe}_{12-2 \mathrm{x}}$ $\mathrm{Co}_{x-y} \mathrm{Sn}_{x} \mathrm{Ni}_{3} \mathrm{O}_{19}$, and (2) varying the $\mathrm{x}$ value and maintaining at $\mathrm{y}=0.5 \mathrm{x}$.

\section{EXPERIMENTAL}

Acidic aqueous solutions containing $\mathrm{BaCl}_{2} \cdot 2 \mathrm{H}_{2} \mathrm{O}, \mathrm{FeCl}_{2} \cdot 6 \mathrm{H}_{2} \mathrm{O}, \mathrm{CoCl}_{2} \cdot \mathrm{H}_{2} \mathrm{O}, \mathrm{SnCl}_{4} \cdot 5 \mathrm{H}_{2} \mathrm{O}$, and $\mathrm{NiCl}_{2} \cdot 6 \mathrm{H}_{2} \mathrm{O}$ were precipitated by adding $\mathrm{Na}_{2} \mathrm{CO}_{3}$ solution. Hexagonal-plated-shaped $\mathrm{BaFe}_{12-2 x} \mathrm{Co}_{x-y} \mathrm{Sn}_{x} \mathrm{Ni}_{y} \mathrm{O}_{1} 9$ particles were obtained by washing, drying, and finally heating the precipates at $600-900^{\circ} \mathrm{C}$ for various times.

\section{RESULTS AND DISCUSSION}

XRD analysis in Figure 1 indicates that the major phases of the precipitates after the heat treatment at $650^{\circ} \mathrm{C}$ is $\alpha-\mathrm{Fe}_{2} \mathrm{O}_{3}$; barium ferrite phase starts forming at $750^{\circ} \mathrm{C}$. Electron micrographs in Figure 2 reveal that the particle shape of the ferrite powders is hexagonal-plated. When the ferrite powders are heat treated at $850^{\circ} \mathrm{C}$ for $1 \mathrm{hr}$, the particle size of the ferrite powders ranges between $0.4 \mu_{*}$ to $0.25 \mu_{\text {. when }}$ the $y$ value ( $\mathrm{Ni}$ ion content) is between 0.2 to 0.8 , while maintaining at $\mathrm{x}=1.0$. Moreover adding $\mathrm{Ni}$ ion decreases the particle size. Thile maintaining at $x=0.8$, adding $N i$ ion to partially replace Co ion, causes the $\sigma$ value of the powders to decrease with the $\mathrm{Ni}$ ion concentration (Figure 3 ). However, adding $\mathrm{Ni}$ ion maximizes the $\mathrm{H}_{c}$ value of the ferrite powders at $\mathrm{y}=0.4$. Furthermore partially replacing $\mathrm{Co}$ ion by $\mathrm{Ni}$ ion does not significantly affect the powders' magnetic properties. If the replacement of $\mathrm{Co}$ ion by $\mathrm{Ni}$ ion is maintained at $50 \%$, i.e. the formula is $\mathrm{BaFe}_{12-2 \times} \mathrm{Co}_{x / 2} \mathrm{Ni}_{x / 2} \mathrm{Sn}_{x} \mathrm{O}_{19}$, the $\sigma$ value and $\mathrm{H}_{\mathrm{c}}$ value (Figure 4) decrease with the $x$ value, i. e. the concentration of ( $\mathrm{Co}, \mathrm{Ni}, \mathrm{Sn}$ ) ions. In particular the $\mathrm{H}_{c}$ value decrease more sharply than the $\sigma$ value. Figures 5 and 6 also reveal that the $\sigma$ value and $H_{c}$ value not only decrease with the $x$ value, but also decrease with the measuring temperatures. The curie temperature of the ferrite powders are found about $450^{\circ} \mathrm{C}$ for $\mathrm{x}=0$ and $350^{\circ} \mathrm{C}$ for $\mathrm{x}=0.8$. 


\section{References}

[1] X. Sueto, H. Sakumoto, A. Suzuki, and M. Sugimoto, "Ferrites," p.964. Proc. 6th International Conf. on Ferrites, Tokyo, 1992.

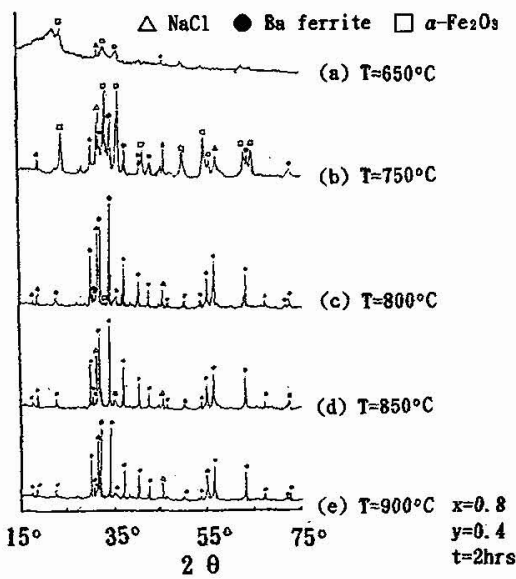

Figure 1 X-ray diffraction patterns of powders heat treated at various temperatures

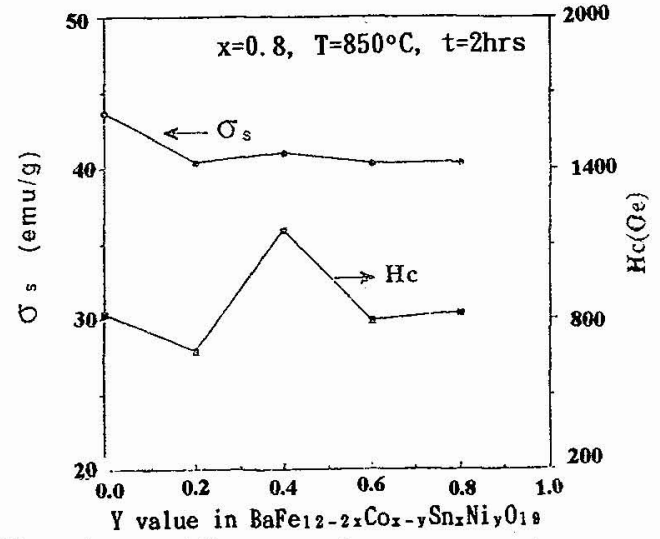

Figure $3 \quad \sigma_{s}$ and $H_{c}$ values of powders at various $y$ values

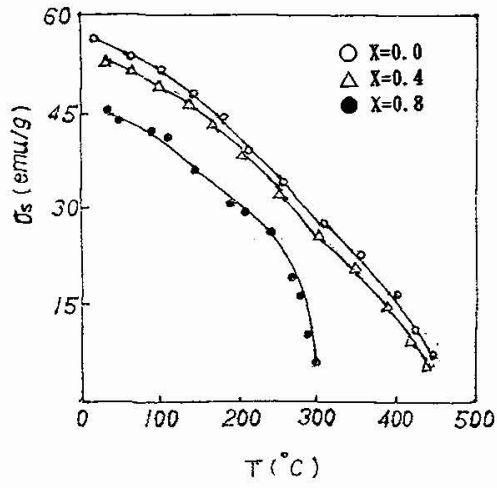

Figure $5 \quad \sigma_{s}$ values of powders at various temperatures

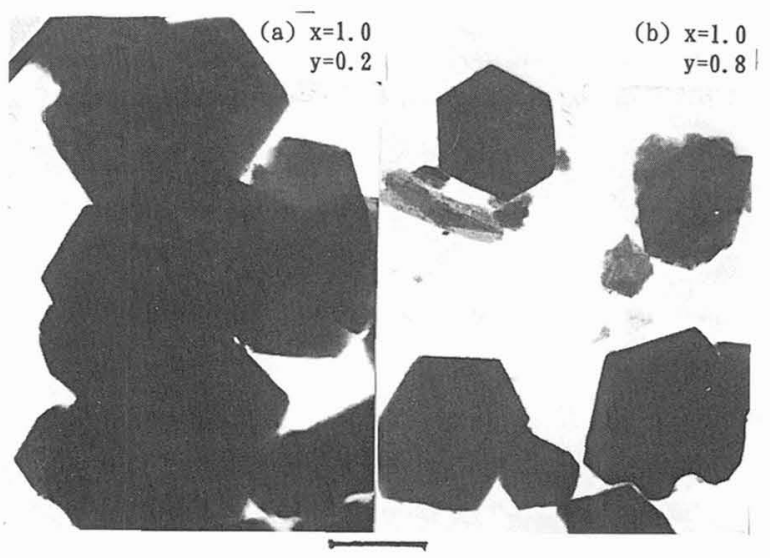

Figure 2 Electron micrographs of powders at various $\mathrm{x}$ values ( $\mathrm{Ni}$ contents)

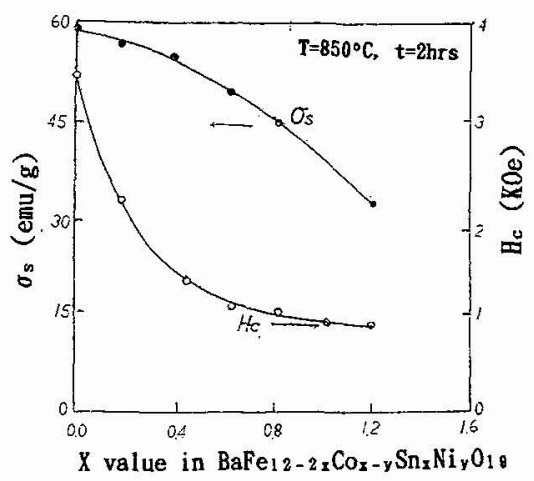

Figure $4 \quad \sigma_{s}$ and $H_{c}$ values of powders at various $x$ values

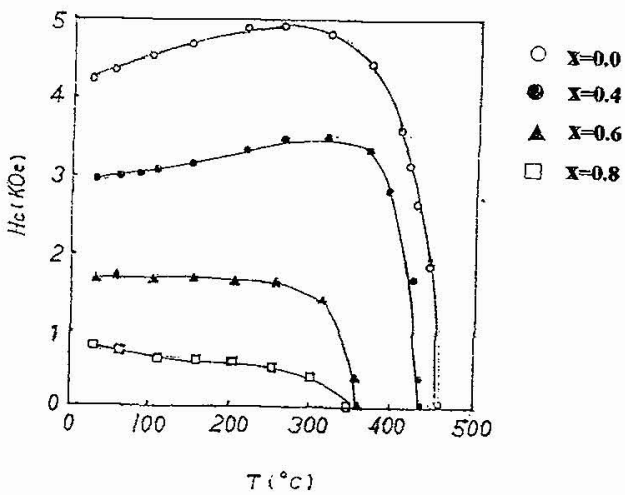

Figure $6 \quad \mathrm{H}_{\mathrm{c}}$ values of powders at various temperatures 